\title{
SOBRE A NOÇÃO DE REPRESENTAÇÃO EM S. MOSCOVICI E F. VARELA ${ }^{1}$
}

Beatriz Sancovschi

Universidade Federal do Rio de Janeiro, Rio de Janeiro, Brasil

RESUMO: A partir do encontro entre a teoria das representações sociais de Serge Moscovici e a abordagem enativa de Francisco Varela, propõe-se a análise da noção de representação. Enquanto a teoria das representações sociais defende e positiva a noção de representação, a abordagem enativa constitui-se e afirma-se a partir da crítica aos paradigmas informacional e representacional. Será que se trata da mesma noção de representação? O objetivo é entender o lugar e o sentido atribuído à noção de representação em ambas as teorias. A distinção feita por Varela entre o sentido forte e fraco de representação será de extrema relevância.

PALAVRAS-CHAVE: Representação social; cognição; Varela; Moscovici.

\section{ON THE NOTION OF REPRESENTATION IN S. MOSCOVICI AND F. VARELA}

ABSTRACT: An analysis of the notion of representation is proposed from the encounter of Serge Moscovici's theory of social representations and Francisco Varela's enactive approach. While the theory of social representations defends and stands for the notion of representation, the enactive approach constitutes and asserts itself from the criticism of informational and representational paradigms. Is the notion of representation the same in both cases? The objective is to understand the place and meaning attributed to the notion of representation in both theories. The distinction established by Varela for the meaning of strong and weak representation will be extremely relevant here.

KEYWORDS: Social representation; cognition; Varela; Moscovici.

O presente trabalho surge como proposta a partir do encontro entre a teoria das representações sociais de Serge Moscovici e a abordagem enativa de Francisco Varela. Em comum elas têm o interesse pelo conhecimento do senso comum e a aposta de que este tipo de conhecimento não se constitui como exceção. Moscovici quer entender como o senso comum se apropria dos conhecimentos produzidos nas mais diversas áreas, conferindo-lhes sentido através da criação das representações sociais. Já Varela quer compreender como o processo de conhecimento acontece na vida cotidiana e não em situações artificiais. Estas diferenças na posição do problema podem ser explicadas, a nosso ver, por seus interlocutores. Moscovici propõe sua teoria no interior das discussões da psicologia social, enquanto Varela trabalha na interlocução com a biologia e as ciências cognitivas. Embora seja interessante uma análise das aproximações e diferenças em relação a colocação do problema nestas duas teorias, interessa-nos aqui uma outra questão. Trata-se do valor atribuído à noção de representação nas teorias de Moscovici e de Varela. Enquanto a teoria das representações sociais defende e positiva a noção de representação, a abordagem enativa constitui-se e afirma-se a partir da crítica ao paradigma informacional e representacional. É importante ressaltar o caráter introdutório e novo desse esforço. Neste sentido, o presente artigo aponta para a abertura de um novo campo de interlocução.

Embora esse não seja o nosso foco, não desconsideramos aqui as discussões que já vêm sendo realizadas no interior do campo da psicologia social entre a teoria das representações sociais e a psicologia discursiva inglesa (Potter \& Edwards, 1999; Potter \& Litton, 1985). Dentre os pesquisadores ingleses destacam-se grupos que efetivamente se opõem à teoria das representações sociais, como é o caso dos que defendem a psicologia discursiva radical ("Radical Discursive Psychology") para quem a psicologia é um sistema ideológico a ser desconstruído (Parker \& Shotter, 1990), rejeitando qualquer possibilidade de complementaridade com outras abordagens (Potter, 1998). E aqueles que baseados na tradição da análise do discurso francesa vêem na teoria das representações sociais um avanço no campo da psicologia social (Potter \& Edwards, 1999; Potter \& Litton, 1985; Potter \& Wetherell, 1998), mas, ainda a consideram, uma teoria fraca e ambígua: "Apesar do indubitável potencial dessas idéias, existe uma gama de ambigüidades e problemas que subjazem a teoria e seus apontamentos, o que reduz sua efetividade na explicação sóciopsicológica" (Potter \& Litton, 1985, p. 81). ${ }^{2}$

\section{Abordagem Enativa de F. Varela e a Crítica à Representação}

A crítica ao paradigma da representação constitui a marca singular dos trabalhos de F. Varela. Desde o momento da formulação da teoria da autopoiese, nos anos de 1970, quando ainda trabalhava em conjunto com seu professor e colega Humberto Maturana, esta crítica já se fazia presente. Data dessa época a definição do conhecer 
como uma ação efetiva do ser no mundo, que constitui ao mesmo tempo o ser e seu mundo de sentido, ou seu domínio estrutural. É desta época também o aforismo ser $=$ fazer $=$ conhecer $($ Maturana $\&$ Varela, 1995). Contudo, foi nos anos de 1980, com a abordagem enativa, em seu trabalho independente, que a crítica à representação tornouse mais enfática (Costa, 1993). Nesta época, noções como co-engendramento e breakdown ganharam destaque, enfatizando a natureza circular e sem fundamento do fenômeno cognitivo (Varela, Thompson \& Rosch, 2003). Mas a qual representação Varela se refere? Por que propor uma teoria do conhecimento contra o modelo da representação?

Em relação à primeira questão, o próprio Varela oferece uma resposta através da distinção entre a representação em sentido fraco e a representação em sentido forte (Varela, 1990, p. 79; Varela et al., 2003, p. 144). A representação em sentido fraco diz respeito ao uso puramente semântico e pragmático do conceito. A representação aparece aí como uma construção ou uma interpretação. Ela se refere a tudo o que talvez possa ser compreendido a respeito de alguma coisa. Nas palavras de Varela: "Ele se refere a qualquer coisa que possa ser interpretada como sendo a respeito de alguma outra. Esse é o sentido de representação como construção, considerando-se que nada é sobre nenhuma outra coisa sem de algum modo construí-la" (Varela et al., 2003, p. 144). Já o sentido forte assume compromissos epistemológicos e ontológicos. $\mathrm{Na}$ tentativa de construir uma teoria completa sobre a percepção, a linguagem ou a cognição, acabou-se operando uma generalização do sentido fraco e, aquilo que era um uso puramente pragmático, assumiu características definitivas. Ao trabalhar com o sentido forte de representação, assumimos que o mundo está dado desde sempre, que ele é pré-determinado e independe de qualquer atividade cognitiva. A atividade de conhecimento se resume à realização de representações mentais de algo que está dado, podendo ser avaliado a partir da correspondência com esta realidade (Varela et al., p. 145).

A objeção de Varela recai, não sobre o sentido fraco, mas sobre o sentido forte da representação. No que diz respeito ao sentido fraco, ele afirma que nós o utilizamos cotidianamente, sem maiores preocupações. O problema está no sentido forte, pois ele parte do pressuposto epistemológico e ontológico de que existe um mundo dado e que a nossa vida e a nossa atividade cognitiva se limita a apreender isto que está dado:

Para as escolas representacionistas, uma entidade cognitiva é globalmente lançada para um mundo preexistente. Esta entidade só irá sobreviver na condição de possuir um mapa e de aprender a agir em função dele. Em termos científicos, isto quer dizer que o mapa é um sistema de representação que é, ou inato (a propósito, digamos assim, do espaço, do tempo, das formas e dos odores) ou adquirido por aprendizagem (os esquemas motores e emocionais) $e$ atualizado (aprendizagem de uma língua específica ou de uma tarefa) durante a ontogênese (Varela, 1990, p. 81).

A recusa à representação em seu sentido forte reflete uma postura ética e política que atravessa a obra do autor chileno (Sancovschi, 2005). A partir desta noção colocase a idéia de um mundo que, não importa o que façamos, não se modifica. Diante desse mundo pré-definido temos duas opções: ou apreendemos (representamos) adequadamente suas características e nos adequamos a ele, ou não, e seremos seres desajustados.

Respondendo a segunda questão, ou seja, se quisermos compreender de onde surge a discussão a respeito da representação na obra de F. Varela é interessante retomar o contexto de onde nasce, primeiro a teoria da autopoiese e, em seguida, a abordagem enativa.

Varela é um biólogo de formação que se interessa pela questão do conhecimento. Acontece que nas décadas de 1950 começa no cenário científico algo que veio a se chamar "revolução cognitiva" (Gardner, 1995). Os primeiros anos foram marcados pela cibernética e pela elaboração de diversas hipóteses sobre o que seria a cognição e o conhecer. Era também o momento de aparecimento dos primeiros computadores. Assim, não tardou para que a cognição fosse pensada como uma computação lógica. Nesses primeiros anos, o entendimento do que seriam essas computações e por conseguinte a cognição era muito variado. A partir do movimento cognitivista nos anos de 1960, a idéia de que a cognição era uma computação simbólica realizada por regras lógicas, de maneira seqüencial, ganhou força e assumiu a posição de teoria hegemônica. A partir daí, a teoria da informação e o modelo da representação, foram transformados em paradigmas para o entendimento da cognição. Conhecer era representar um mundo dado através de regras lógicas.

O cognitivismo, por questões diversas, acabou difundindo-se por diferentes áreas e, por uma extrapolação, os paradigmas representacionais e informacionais passaram a definir não apenas a cognição, mas também o ser vivo e o humano (Varela, 1990). Cognição, vivo e humano passaram a ser entendidos e explicados a partir de mecanismos de processamento de informação, isto é, como máquinas de entradas e saídas (inputs - outputs) que representam o mundo através de símbolos, possibilitando uma ação adequada neste mundo.

A partir dos trabalhos no laboratório de biologia-como exemplo citamos os experimentos sobre a percepção visual em animais - Varela cada vez mais se convencia de que os paradigmas informacionais e representacionais eram insuficientes para dar conta tanto da cognição quanto do vivo. $^{3}$ 
A análise da percepção visual em diferentes espécies de animais aponta para diversas dimensionalidades na visão de cores. Nós, humanos, temos uma visão de cores tricromática: em função de certas características de nossos fotoreceptores e da configuração que eles assumem no nosso organismo, são necessárias três dimensões para representar a visão de cores que temos. No entanto, existem alguns animais dicromatas, como os esquilos e os coelhos; e outros tetracromáticos, como os pombos e patos; podendo alguns, serem pentacromáticos. Qual seria, então, a cor do mundo? Sobre isso Varela et al. comentam:

Quando as pessoas ouvem falar dessa evidência de tetracromia, elas respondem perguntando 'Quais são as outras cores que esses animais enxergam?'. Essa pergunta é compreensivel, mas ingênua, se entendida como sugerindo que os tetracromatas simplesmente são melhores em ver cores do que nós. Devemos lembrar, entretanto, que um espaço de quatro dimensões de cores é fundamentalmente diferente do tridimensional (2003, p. 184).

Não se trata, portanto, de que os animais dicromatas vêem menos e os tetracromatas vêem mais, mas sim de realidades ou mundos diferentes: "Não vemos o 'espaço' do mundo - vivemos nosso campo visual. Não vemos as 'cores' do mundo - vivemos nosso espaço cromático" (Maturana \& Varela, 1995, p. 66). O mundo não está aí dado, pronto para ser representado, mas emerge de maneira co-engendrada com os organismos vivos.

Embora a idéia de co-engendramento apareça com maior ênfase no desenvolvimento da abordagem enativa, ela já estava presente na teoria da autopoiese através da noção de clausura operacional (Costa, 1993; Kastrup, 1999; Sancovschi, 2003, 2005). No entanto para entender o coengendramento a partir da clausura operacional é importante jamais perder de vista o caráter processual que singulariza o funcionamento autopoiético. Caso contrário, correse o risco de pensar o fechamento operacional como um limite intransponível ou como isolamento. Sobre isso, Varela nos adverte: "clausura não é fechamento" (1989, p. 217). E, Kastrup esclarece:

Os sistemas são auto-referentes, autoproduzidos, mas não são sistemas isolados. Ao contrário, a abertura é sua marca maior, aparecendo já no momento da produção da unidade. Além disso, tal modo de constituição não é jamais ultrapassado, pois a unidade mantém-se em constante processo de redefinição de suas fronteiras, e o dentro está em contínua relação de osmose com o fora (Kastrup, 1999, p. 124).

O fora neste caso é tanto o meio, quanto os outros organismos com os quais o sistema autopoiético mantém contato (acoplamento estrutural) e trocas permanentes. A crítica, portanto, de que a abordagem enativa seria solip- sista não possui qualquer fundamento (Costa, 1993; Verheggen \& Baerveldt, 2007).

T. Verheggen e C. Baerveldt propuseram em recente artigo um encontro entre a teoria das representações sociais e a abordagem enativa (2007). Para os autores a ênfase na ação seria um ponto de intercessão entre as duas teorias. Contudo, a teoria das representações sociais em questão é a de W. Wagner. Wagner se apóia em Moscovici, no entanto avança em relação a ele: "Wagner apresenta uma variante da teoria das representações sociais na qual a natureza construcionista das representações sociais e do conhecimento é ainda mais radicalmente extrapolada. Não existe mundo social antes ou acima de pessoas agindo e representando" (Verheggen \& Baerveldt, p. 6). Sem entrar nos pormenores do artigo, interessa-nos aqui destacar que Verheggen e Baerveldt ao se proporem entender o estatuto do social em questão nas representações sociais sugerem pensar o social como domínio consensual, tal como desenvolvido por Maturana e Varela (1995):

A abordagem enativa está apta a ser mais radicalmente social na medida em que oferece um critério para o social que não é derivado nem de um espaço representacional já compartilhado, nem de um conteúdo mental individual. Ela postula que a 'representação' pertence a um nível de descrições e que, o que pode ser descrito é trazido à cena por operações de distinção do ponto de vista do observador (Verheggen \& Baerveldt, 2007, p. 19).

Foi, portanto, devido uma insatisfação com as teorias vigentes sobre o vivo e a cognição que Varela começou, primeiro junto com Maturana a trabalhar na teoria da autopoiese, e depois, já separado de seu professor, refinando ainda mais a sua crítica, passou a formulação da abordagem enativa. A autopoiese e a enação compartilham de uma mesma intuição: sujeito e mundo não são dados de antemão, mas são produzidos de maneira coengendrada. Neste sentido não existe lugar na teoria de Varela para a representação em sentido forte.

Em sua apresentação da teoria da autopoiese Maturana e Varela esclarecem:

Na base de tudo o que diremos está essa constante consciência de que o fenômeno do conhecer não pode ser equiparado à existência de 'fatos' ou objetos lá fora, que podemos captar e armazenar na cabeça. A experiência de qualquer coisa 'lá fora' é validada de modo especial pela estrutura humana, que torna possivel 'a coisa' que surge na descrição (1995, p. 68).

Sobre a abordagem enativa Varela afirma:

A insatisfação principal daquilo a que chamamos a abordagem da enação é simplesmente a ausência completa, até hoje, de senso comum na definição da cognição. Para o cognitivismo, como para o cone- 
xionismo atual, o critério de avaliação da cognição é sempre a representação adequada de um mundo exterior predeterminado. Falamos em elementos de informação que correspondem a propriedades do mundo (como as formas e as cores), ou em resolução de problemas bem definidos que implicam um mundo bem elaborado (1990, p. 72).

\section{Teoria das Representações Sociais de S. Moscovici e seu Conceito de Representação}

A teoria das representações sociais, fundada por S. Moscovici nos anos de 1960, surge no contexto de desenvolvimento da psicologia social européia. Através desta teoria, também conhecida como psicologia social do conhecimento, Moscovici opera um deslocamento no foco de apreensão dos fenômenos psicológicos, sociais e cognitivos.

Em função de nossa tradição científica cartesiana, estamos acostumados a olhar para o mundo e para nós mesmos através de dicotomias, como, por exemplo, sujeitoobjeto e indivíduo-sociedade. Tal forma de apreensão gerou no campo da psicologia uma separação entre o psicológico e o social. Moscovici, no entanto, parte de um outro lugar. Ao invés de começar pelas dicotomias, ele inicia pelas relações que tornam possíveis o aparecimento de "sínteses" 4 temporárias que dão forma a sujeitos, objetos, indivíduos e sociedades. Nada é dado de antemão, tudo é produzido na relação (Jovchelovitch, 1998, 2004). Dessa forma, Moscovici possibilita que o psicológico seja reunido com o social, inventando uma nova forma de fazer psicologia social. Tudo isso decorre do interesse do autor em explicar como se produz e se transforma o conhecimento, especialmente o conhecimento do senso comum.

Embora Moscovici distinga o conhecimento científico do conhecimento do senso comum, ele não estabelece entre eles qualquer hierarquia. $\mathrm{O}$ conhecimento do senso comum não é um conhecimento corrompido ou distorcido, mas é o lugar onde o conhecimento científico se junta ao senso comum produzindo redes de comunicação, tornando a sociedade viva (Moscovici, 1988). Citamos: "O problema para mim se tornou o seguinte: como o conhecimento científico é transformado em conhecimento comum, ou espontâneo?" (Moscovici, 2003, p. 310). Ou ainda:

Desse modo, quando comecei minha pesquisa na França, tentei compreender e reabilitar o pensamento comum e o conhecimento comum. Ainda mais, não os considerei como algo tradicional, ou primitivo, como mero folclore, mas como algo muito moderno, originando-se parcialmente da ciência, como a configuração que assume quando se torna parte da parcela da cultura. Vi a transformação do conhecimento científico em senso comum como uma área de estudo possível e excitante (Moscovici, 2003, p. 311).
Antes de avançar, chamamos atenção para essa operação de deslocamento que singulariza a proposta de Moscovici. A nosso ver, a consideração desse deslocamento é essencial para a adequada compreensão do estatuto da representação no âmbito da teoria das representações sociais. Se sujeito e objeto não são pólos dados de antemão, como pensar o conceito de representação? Parece, a princípio, que não se trata aí da "representação em seu sentido forte".

Compreender o estatuto da representação no contexto da teoria das representações sociais não é tarefa fácil. Isto porque Moscovici não esteve e, não está preocupado com este tipo de esclarecimento. Freqüentemente o autor é acusado de imprecisão (Harré, 1984; Moscovici, 1988, 2003) e ambigüidade (Potter \& Litton, 1985). No entanto, longe de ver aí um problema, ele afirma ser isso uma virtude da teoria. É a pouca rigidez na definição de conceitos que permite à teoria um maior alcance na compreensão dos fenômenos. Assim, a fim de compreender o estatuto da representação na teoria das representações sociais, vamos percorrer aquilo que consideramos serem pistas deixadas pelo autor.

Escolhemos como primeira pista, a crítica que Moscovici tece em relação à noção de representação, tal como trabalhada pela psicologia cognitiva dos anos de 1950. Embora o autor revele, em seus textos, um interesse pela cibernética, destacando as contribuições que a revolução cognitiva trouxe para as ciências, ele afirma que a psicologia cognitiva da década de 50, por questões diversas, acabou simplificando excessivamente a noção de representação. Em outras palavras, a psicologia cognitiva da década de 50 passou a trabalhar com uma concepção de representação que não considera nem o social e muito menos o simbólico, ${ }^{5}$ aspectos essenciais para a definição da noção de representação social. Citamos:

A revolução cognitiva, na psicologia, iniciada na década de 1950, legitimou a introdução de conceitos mentalistas, que tinham sido proscritos pelas formas militantes do comportamentalismo, que dominou a primeira metade do século vinte e, subseqüentemente, as idéias de representações foram o elemento central na emergência da ciência cognitiva, nas duas últimas décadas. Mas a partir desta perspectiva, a representação foi geralmente vista num sentido muito restrito, como construção mental dum objeto externo. Embora isso tenha permitido o desenvolvimento dum cálculo informacional, em que representações foram termos centrais, o caráter social, ou simbólico, das representações raramente figurou em tais teorias [grifo nosso] (Moscovici, 2003, p. 19).

Ainda procurando se diferenciar de certa concepção de representação, Moscovici afirma:

Enquanto as formas 'clássicas' de psicologia cognitiva... tratam a representação como um elemento 
estático da organização cognitiva, na teoria da representação social o próprio conceito de representação possui um sentido mais dinâmico, referindo-se tanto ao processo pelo qual as representações são elaboradas, como às estruturas de conhecimento que são estabelecidas (2003, p. 20).

Esta distinção é, para nós, uma pista importante, pois é também justamente em relação à noção de representação, tal como o cognitivismo a entende, que a crítica de F. Varela incide. Nas palavras de Kastrup: "Fazendo um balanço do cognitivismo computacional, Francisco Varela (1990) afirma que seu aspecto negativo foi operar um resfriamento formal da cognição abstrata, independente e dissociada tanto do corpo quanto dos afetos e da história do sistema" (2005, p. 224). Assim, embora Moscovici não desconsidere a existência de uma realidade externa, ele defende que ela só terá importância na medida em que for representada socialmente pelos sujeitos. Isto implica produção de sentido e transformação. As representações sociais são criações coletivas que se fazem na comunicação e, ao mesmo tempo, a possibilitam.

A segunda pista refere-se à origem do termo representações sociais. Esta pista talvez esclareça porque Moscovici insiste na manutenção de um termo tão controverso como é a noção de representação. De acordo com o autor, o conceito de representação social deriva do conceito de "representação coletiva" de E. Durkheim. Desse modo, ele afirma sua filiação em relação à sociologia de Durkheim. No entanto defende, em relação a ela, algumas diferenças.

Durkheim propôs, através do conceito de representações coletivas, uma matriz subjacente às nossas crenças, conhecimento e linguagem. Neste ponto há uma aproximação entre o conceito de Durkheim e o de Moscovici. No entanto, como Durkheim estava preocupado em estabelecer a sociologia como uma ciência autônoma, ele acabou defendendo uma separação radical entre representações individuais e representações coletivas. Segundo ele, caberia à psicologia o estudo das primeiras, enquanto a sociologia ficaria encarregada de estudar as últimas. Ao separar as representações individuais das representações coletivas, Durkheim acabou impossibilitando que os processos de transformação e mudança das representações coletivas fossem examinados. É importante destacar, contudo, que a questão da dinâmica de transformação das representações não era foco de interesse de Durkheim. Através do conceito de representações coletivas o autor queria apenas explicar como a sociedade se mantém coesa, como ela se conserva. É Moscovici que com o conceito de representações sociais começa a interrogar sobre a dinâmica e transformação das representações. Moscovici quer entender e explicar como as coisas mudam na sociedade. Portanto, diferentemente de Durkheim, que parte das representações coletivas para explicar a sociedade, Moscovici se vê obrigado a explicar o processo de construção das representações sociais. Citamos o comentário de G. Duveen:

Enquanto Durkheim vê as representações coletivas como formas estáveis de compreensão coletiva, com o poder de obrigar que pode servir para integrar a sociedade como um todo, Moscovici esteve mais interessado em explorar a variação e a diversidade das idéias coletivas nas sociedades modernas, em que as diferenças refletem uma distribuição desigual de poder e geram uma heterogeneidade de representações (2003, p. 15).

Portanto, apesar de considerar a dívida em relação ao Durkheim, se quisermos compreender o alcance da noção de representação na teoria das representações sociais, é preciso considerar outras filiações, como L. Lévy-Bruhl, J. Piaget e L. S.Vygotski.

Lévy-Bruhl, ao chamar atenção para as diferenças entre as representações coletivas de diferentes sociedades, deu a esta noção uma maior concretude. As representações coletivas não são universais e nem estáticas, elas assumem diferentes formas em diferentes sociedades. Como explicar isso? É por aí que Moscovici avança, defendendo sua noção de representações sociais.

No que se refere aos trabalhos de Piaget e Vygotski, Moscovici retira deles principalmente a inspiração para pensar o mecanismo de formação das representações. Aqui a obra de Piaget - com a qual Moscovici tem maior contato (Moscovici, 2003, p. 283-284) - ganha especial destaque. Citamos Moscovici:

Se a psicologia do desenvolvimento está interessada,
no curso das vidas das crianças, com a transforma-
ção de suas representações 'espontâneas' em repre-
sentações científicas e racionais, parece-me que a
psicologia social deve enfrentar o processo inverso,
isto é, estudar como representações científicas são
transformadas em representações comuns (2003, p.
206).

Uma terceira pista refere-se ao momento em que as representações sociais tornam-se uma questão. Quando as formas de legitimação dos conhecimentos e de produção de sentidos não estão garantidas por nenhuma instância totalizadora, como por exemplo, a ordem divina ou o Estado absoluto, é que as representações sociais aparecem como questão. Na medida em que não há nada que sobrecodifique o mundo, garantindo-lhe uma ordem e um sentido, cabe ao social dotá-lo de sentido e de ordem. Dessa forma, cabe às representações sociais realizarem o trabalho de elaboração do novo, do estranho, do não-familiar conferindo-lhe sentido e inteligibilidade. É por isso que Moscovici afirma que a principal função das representações sociais é tornar o não-familiar, familiar. Este trabalho é feito coletivamente, nas conversações ou comunicações cotidianas. No entanto, é interessante destacar que estas 
conversações ou comunicações só são possíveis porque existem representações sociais. Revela-se aí um dos paradoxos desse conceito e fenômeno tão complexo. Nas palavras de Moscovici:

\begin{abstract}
A motivação para a elaboração de representações sociais não é, pois, uma procura por um acordo entre nossas idéias e a realidade de uma ordem introduzida no caos do fenômeno ou, para simplificar, um mundo complexo, mas a tentativa de construir uma ponte entre o estranho e o familiar; $e$ isso à medida que o estranho pressuponha uma falta de comunicação dentro do grupo, em relação ao mundo, que produz um curto-circuito na corrente de intercâmbios e retira do lugar as referências da linguagem (2003, p. 207).
\end{abstract}

Dois são os processos que tornam possível esse movimento de familiarização ou de construção da representação social. São eles: a ancoragem e a objetivação.

A ancoragem é o processo que aproxima aquilo que é estranho, perturbador, sem sentido, aquilo que não pode ser comunicado, a alguma categoria já existente. Neste processo é importante defender a potência do estranhamento, não se deixando ser totalmente sobrecodificado pelas categorias pré-existentes. ${ }^{6}$ Assim, o processo de ancoragem deve considerar ao mesmo tempo o movimento de familiarização do não-familiar e o de des-familiarização do familiar (Arruda, 2000) ${ }^{7}$. Já a objetivação é o processo pelo qual as representações assumem uma forma concreta, seja através de imagens produzidas, seja através de objetos: "Para começar, objetivar é descobrir a qualidade icônica de uma idéia, ou ser impreciso; é reproduzir um conceito em uma imagem. Comparar é já representar, encher o que está naturalmente vazio, com substância" (Moscovici, 2003, p. 71-72).

Por tudo o que foi dito, pelas pistas seguidas, parece possível afirmar que a noção de representação assume na teoria da representação social de S. Moscovici o sentido de criação de um mundo comum. Não se trata, portanto, como no cognitivismo, de considerar um mundo externo, dado desde sempre, que deva ser representado pelo sujeito, permitindo uma ação adequada neste mundo. Para a teoria das representações sociais, as representações possibilitam a ação no mundo, mas não em um mundo dado que deve ser apreendido, mas num mundo criado e compartilhado coletivamente. Neste sentido a noção de representação com a qual Moscovici trabalha se afasta da idéia de uma re-apresentação, se por isso entendemos uma repetição sem novidade ou criação.

Destacamos que a leitura proposta aqui da teoria de S. Moscovici é uma das inúmeras possíveis. Conforme ressaltamos anteriormente, Moscovici não se preocupa com um esclarecimento detalhado de sua abordagem, deixando que pesquisadores e teóricos que trabalham com a sua teoria o façam. Para Moscovici esta é justamente uma das dimensões positivas de seu trabalho. Autores da psicologia discursiva inglesa discordam radicalmente da postura adotada por Moscovici. Para eles, a imprecisão é uma falta grave que compromete a teoria e suas pesquisas. Assim, eles se dedicam, em diferentes artigos, a rever a teoria das representações sociais e propor esclarecimentos e soluções à luz da psicologia discursiva. Embora concordemos que a falta de precisão da teoria de Moscovici pode gerar ambigüidades e deixar desnorteados os pesquisadores que trabalham com ela, não nos parece que as avaliações e soluções dos pesquisadores da psicologia discursiva sejam as únicas, ou as mais acertadas. A análise das críticas tecidas à teoria das representações sociais pela psicologia discursiva inglesa extrapola os limites deste artigo. No entanto, acreditamos que o presente trabalho pode contribuir para esta discussão, sobretudo no que diz respeito às noções de cognição e representação. Em relação a essas noções nos parece que a crítica da psicologia discursiva é apressada, não considerando as nuances existentes no campo de estudos da cognição.

\section{Considerações Finais}

Longe de pretender ter esgotado o tema proposto, acreditamos que começamos a avançar na direção de um diálogo entre duas teorias que cada vez mais assumem importância no cenário da psicologia. Certamente não contemplamos todos os vieses de análise possíveis. No entanto, nos parece que isto que conseguimos reunir dá indicação que a teoria das representações sociais, apesar de ter no nome a palavra representação, seja por sua crítica ao cognitivismo, seja por sua crítica a idéia de um mundo dado, aproxima-se, mais do que se afasta, da abordagem enativa de Varela.

As representações sociais trabalham com um sentido de representação como interpretação e criação, tratando-se aí, portanto, do que Varela chama de representação em sentido fraco. $\mathrm{O}$ conceito de representações sociais, tal como apresentado por Moscovici, recusa justamente a idéia de um mundo dado a priori, apostando na produção, a partir da comunicação, de um mundo comum. Ressaltamos, contudo, que sempre que se trabalha com a noção de representação corre-se o risco de efetuar generalizações, tomando isto que é resultado de uma construção como algo dado de antemão. ${ }^{8}$

Note-se que a aposta na aproximação de Varela e Moscovici é uma política de pesquisa. Poderíamos ter nos concentrado nas críticas, no que há de diferente ou insuficiente em uma ou outra teoria. No entanto, menos do que defender um território, estamos interessados na criação de um campo de diálogo que permita pensarmos juntos, novas questões. Neste sentido Varela ilumina a teoria de Moscovici e, Moscovici fecunda a teoria de Varela. Este exercício poderá permitir inclusive uma posterior revisão 
das críticas freqüentemente tecidas em relação à teoria das representações sociais.

\section{Notas}

\section{Apoio CNPq}

2 A tradução deste texto é nossa, assim como a de todos outros textos em idioma estrangeiro citados.

3 Para mais detalhes ver Maturanae Varela(1995)e Varela, Thompson e Rosch (2003).

4 É importante esclarecer que a utilização do termo "síntese" é uma interpretação nossa. Este termo está fortemente vinculado a um vocabulário próprio de abordagens dialéticas. Ressaltamos porém que quando Moscovici elabora a teoria das representações sociais, ele está em franca ruptura com seu passado marxista. Neste sentido ele tenta se afastar de tudo o que se aproxime dele (classe social, dialética, etc.). Apesar disso seu pensamento continua marcado por um veio que não ignora o peso das contradições concretas e materiais sobre a vida dos sujeitos sociais.

5 É importante esclarecer que o sentido atribuído aqui ao simbólico difere daquele utilizado pelo cognitivismo computacional. O cognitivismo entende o conhecer como um processamento simbólico por regras lógicas, onde os símbolos representam aquilo que eles significam (Varela et al., 2003, p. 56). Assim, o simbólico para o cognitivismo computacional é o lugar da representação em sentido forte - os símbolos correspondem a certos aspectos do mundo - e não o lugar da emergência do singular, do sentido. Já quando Moscovici afirma que o simbólico não foi tratado pela psicologia cognitiva da década de 50 , ele se refere ao simbólico como campo de produção de sentido que é sempre singular, que se faz na comunicação e, portanto, é atravessado pela linguagem.

6 Sobre esta questão recomendamos ver o texto de Morant e Rose (2000). Neste texto as autoras, através de um estudo sobre a loucura, colocam em questão a possibilidade de familiarização do estranho.

7 Destacamos que a questão da potência do estranhamento e da des-familiarização do familiar, são pontos que Moscovici não desenvolveu. No entanto, pesquisadores que trabalham com a sua teoria o estão fazendo. Neste sentido a observação realizada por Howarth (2006) - de que embora a teoria das representações sociais de S. Moscovici tenha potencial para se afirmar como uma teoria crítica da ordem social; ela precisa ser melhor desenvolvida - mostra-se pertinente.

8 C.f. Verheggen e Baerveldt (2007).

\section{Referências}

Arruda, A. (2000). O ambiente natural e seus habitantes no imaginário brasileiro: Negociando a diferença. In A. Arruda (Ed.), Representando a alteridade (pp. 17-46). Petrópolis, RJ: Vozes.

Costa, R. (Ed.). (1993). Limiares do contemporâneo: Entrevistas. São Paulo, SP: Escuta.

Duveen, G. (2003). Introdução: O poder das idéias. In S. Moscovici (Ed.), Representações sociais: Investigação em Psicologia Social (pp.7-28). Petrópolis, RJ: Vozes.

Gardner, H. (1995). A nova ciência da mente: Uma história da revolução cognitiva. São Paulo, SP: Editora da Universidade Estadual Paulista.
Harré, R. (1984). Some reflections on the concept os 'social representation'. Social Research, 51, 927-938.

Howarth, C. (2006). A social representation is not a quiet thing: Exploring the critical potecial of social representations theory. British Journal of Social Psycology, 45, 65-86.

Jovchelovitch, S. (1998). Representações Sociais: Para uma fenomenologia dos saberes sociais. Psicologia \& Sociedade, 10(1), 54-68.

Jovchelovitch, S. (2004). Psicologia social, saber, comunidade e cultura. Psicologia \& Sociedade, 16(2), 20-31.

Kastrup, V. (1999). A invenção de si e do mundo: Uma introdução do tempo e do coletivo no estudo da cognição. Campinas, SP: Papirus.

Kastrup, V. (2005). A Psicologia no contexto das ciências cognitivas. In A. Jacó-Vilela, A. Ferreira \& F. Portugal. História da Psicologia: Rumos e percursos (pp. 215-238). Rio de Janeiro, RJ: Nau.

Maturana, H., \& Varela, F. (1995). A árvore do conhecimento. Campinas, SP: Psy.

Morant, N., \& Rose, N. (2000). Loucura, multiplicidade e alteridade. In A. Arruda (Ed.), Representando a alteridade (pp. 129-148). Petrópolis, RJ: Vozes.

Moscovici, S. (1988). Notes towards a description of social representations. European Journal of Social Psychology, 18, 211-250.

Moscovici, S. (2003). Representações Sociais: Investigações em Psicologia Social. Petrópolis, RJ: Vozes.

Parker, I., \& Shotter, J. (1990). Desconstructing Social Psychology. London: Routledge.

Potter, J. (1998). Discursive Social Psychology: From attitudes to evaluative practices. European Review of social psychology, 9, 233-266.

Potter, J., \& Edwards, D. (1999). Social representations and Discursive Psychology: From cognition to action. Culture \& Psychology, 4(5), 447-458.

Potter, J., \& Litton, I. (1985). Some problems underlying the theory of social representations. British Journal of Social Psychology, 24, 81-90.

Potter, J., \& Wetherell, M. (1998). Social representations, discursive analysis and racism. In U. Flick (Ed.), The Psychology of the social (pp. 138-155). Cambridge, MA: Cambridge University Press.

Sancovschi, B. (2003). Sobre o caminho dos riscos: Repensando o conceito de adaptação. Monografia de Graduação não publicada. Instituto de Psicologia da Universidade Federal do Rio de Janeiro.

Sancovschi, B. (2005). Sobre a aprendizagem: Ressonâncias entre a abordagem enativa de F. Varela e a psicologia histórico-cultural de L. S. Vygotski. Dissertação de Mestrado não-publicada, Programa de Pós-Graduação em Psicologia, Universidade Federal do Rio de Janeiro, RJ.

Varela, F. (1989). Autonomie et connaissance: essai sur lê vivant. Paris: Seuil.

Varela, F. (1990). Conhecer: As ciências cognitivas tendências e perspectivas. Lisboa, Portugal: Instituto Piaget.

Varela, F., Thompson, E., \& Rosch, E. (2003). A mente incorporada: Ciências cognitivas e experiência humana. Porto Alegre, RS: Artmed.

Verheggen, T., \& Baerveldt, C. (2007). We don’t share! The social representation approach, enactivism and ground for an intrisically Social Psychology. Culture \& Psychology, 5(13), 5-27. 
Sancovschi, B. "Sobre a noção de representação em S. Moscovici e F. Varela"

Beatriz Sancovschi é aluna do doutorado do Programa de Pós-Graduação em Psicologia da Universidade Federal do Rio de Janeiro. Endereço para correspondência: Rua Uruguai, 545, apto. 404, Tijuca, Rio de Janeiro, RJ, 20510-060. Telefone: (21) 93756854.

biasan@hotmail.com
Sobre a noção de representação em S. Moscovici e F. Varela

Beatriz Sancovschi

Recebido: 09/11/2006

$1^{\text {a }}$ revisão: 03/04/2007

Aceite final: 07/05/2007 